JKEP

Vol 5, No 2, November 2020

ISSN: 2354-6042 (Print)

ISSN : 2354-6050 (Online)

\title{
Keputusan Masyarakat Dalam Pemilihan Rumah Sakit Untuk Pelayanan Kesehatan Di Wilayah Malang Raya
}

\author{
Ella Mayasari, Nihayatul Munaa, Lailatul Kodriyah, Ida Herawati, Ronal Surya Aditya \\ Sekolah Tinggi Ilmu Kesehatan Kepanjen \\ email : suryaronal@gmail.com
}

\author{
Artikel history \\ Dikirim, Jan $03^{\text {rd }}, 2020$ \\ Ditinjau, Nov $11^{\text {th }}, 2020$ \\ Diterima, Nov $27^{\text {th }}, 2020$
}

\begin{abstract}
Hospital is one of the public facilities used by the Indonesian people in the health sector. A hospital is a health service institution that conducts complete individual health services that provide inpatient, outpatient and emergency services. This research was conducted descriptively Qualitative research using a phenomenological approach was conducted in November 25 to 29 November 2019. data were obtained through in-depth interviews. Stages of analysis Data obtained by in-depth interviews can be analyzed the process of data analysis with Interpretative Phenomenological Analysis (IPA). The population of this study was 11 respondents. The method of selecting participants was carried out using a purposive sampling technique. Age of respondents 25-50 years. The results found 7 themes, namely: Distance, BPJS Class, Rates, services, Doctors, Diseases, Facilities. Conclusion: In Hospital Selection the distance is a major factor in the selection of Hospitals. The next factor is BPJS or health insurance which is owned by each individual in the selection of hospitals because it will be related to tariffs. hospitals that affect the expenditure of individuals who are sick.
\end{abstract}

\begin{abstract}
ABSTRAK
Rumah Sakit adalah salah satu fasilitas umum yang digunakan oleh masyarakat Indonesia dalam bidang kesehatan. Rumah sakit adalah institusi pelayanan kesehatan yang menyelenggarakan pelayanan kesehatan perorangan secara paripurna yang menyediakan pelayanan rawat inap, rawat jalan dan gawat darurat. Penelitian ini dilakukan secara deskriptif Penelitian kualitatif menggunakan pendekatan fenomenologis dilakukan pada bulan bulan November 25 hingga 29 November 2019. data diperoleh melalui wawancara mendalam. Tahapan analisis Data yang diperoleh dengan in-depth interview dapat dianalisis proses analisis data dengan Interpretative Phenomenological Analysis (IPA). Populasi penelitian ini adalah 11 partisipan. Metode pemilihan peserta dilakukan dengan teknik purposive sampling. Usia responden 25-50 tahun . Hasil penelitian menemukan 7 tema, yaitu : Jarak, Kelas BPJS, Tarif, pelayanan, Dokter, Penyakit, Fasilitas. Kesimpulan : Dalam Pemilihan Rumah Sakit, jarak adalah faktor utama pertimbangan dalam pemilihan Rumah Sakit. Faktor selanjutnya adalah BPJS atau asuransi kesehatan yang dimiliki oleh setiap individu dalam pemilihan Rumah sakit karena hal tersebut akan berkaitan dengan tarif. rumah sakit yang mempengaruhi pengeluaran indvidu yang sakit.
\end{abstract}

Kata Kunci : Rumah Sakit, Keputusan, Layanan Kesehatan 


\section{PENDAHULUAN}

Rumah Sakit adalah salah satu fasilitas umum yang digunakan oleh masyarakat Indonesia dalam bidang kesehatan(Aditya, 2019b). Rumah sakit melakukan beberapa jenis pelayanan diantaranya pelayanan medik, pelayanan penunjang medik, pelayanan perawatan, pelayanan rehabilitasi, pencegahan dan peningkatan kesehatan, sebagai tempat pendidikan dan atau pelatihan medik dan para medik, sebagai tempat penelitian dan pengembangan ilmu dan teknologi bidang kesehatan serta untuk menghindari risiko dan gangguan kesehatan sebagaimana yang dimaksud, sehingga perlu adanya penyelenggaan kesehatan lingkungan rumah sakit sesuai dengan persyaratan kesehatan(Aditya et al., 2017). Rumah sakit adalah institusi pelayanan kesehatan yang menyelenggarakan pelayanan kesehatan perorangan secara paripurna yang menyediakan pelayanan rawat inap, rawat jalan dan gawat darurat (Keputusan Menteri Kesehatan Republik Indonesia No. 340/MENKES/PER/III/2010).

Keberadaan Rumah Sakit (RS) sangat penting untuk memberikan pelayanan kesehatan bagi masyarakat. Berdasarkan data Kementerian Kesehatan (Yusuf et al., 2017), jumlah RS di seluruh Indonesia sebanyak 2.813 unit hingga akhir 2018. Jumlah tersebut terdiri atas 2.269 RS Umum dan 544 RS khusus. Sesuai dengan data tersebut diatas masyarakat Indonesia memiliki kebebasan dalam memilih tempat perawatan yang tepat dalam menunjang kesehatan.

Keberadaan rumah sakit yang banyak , memiliki kelebihan dan kekurangan. Dengan masyarakat akan selalu bingung dengan keadaan tersebut. Dengan adanya penelitian ini, menjadi referensi dalam kebijakan bagi penyedia layanan kesehatan khususnya rumah sakit untuk meningkatkan pelayanan. Tujuan dari penelitian ini adalah menggathui hal-hal yang menjadi pertimbangan individu dalam memilih Rumah Sakit.

\section{METODE}

Penelitian ini dilakukan secara deskriptif Penelitian kualitatif menggunakan pendekatan fenomenologis (Aditya, Solikhah and Kurniawan, 2019). Dengan menggunakan metode ini, peneliti ingin mengeksplorasi atau mengungkapkan makna suatu konsep atau fenomena pengalaman berdasarkan kesadaran yang terjadi pada beberapa individu. Penelitian ini dilakukan pada 25 hingga 29 November 2019. Metode 
pemilihan peserta dilakukan dengan menggunakan probabilitas dasar pengambilan sampel dengan teknik purposive sampling, yang dianggap cocok untuk kita kriteria. Sebanyak 11 partisipan yang diwawancarai di Penelitian ini adalah usia produktif berusia 25-50 tahun (diberi kode sebagai P1, P2, P3, P4, P5, P6, P7, P8, P9, P10, P11). Semua peserta adalah warga yang berada di Perumahan Araya, Semua peserta menyatakan keinginan mereka untuk memberikan informasi yang dibutuhkan oleh peneliti untuk mencapai tujuan dari penelitian ini. Pengumpulan data dalam penelitian inidilakukan dengan wawancara mendalam menggunakan suara perekam dan teknik observasi langsung. semua data diperoleh dari mendalamwawancara kemudian dianalisis menggunakan Interpretatif Analisis Fenomenologis (IPA)(Yusuf et al., 2017). Penelitian ini telah mendapat persetujuan komite etik STIKes Kepanjen.

\section{HASIL DAN PEMBAHASAN}

Data yang telah didapatkan ini adalah data dari responden yang homogen dengan kriteria usia 25 sampai 50 tahun, warga yang berada di Perumahan Araya.

Tema 1: Jarak
Dalam pemilihan rumah sakit untuk menunjang kesehatan individu yang pertama yaitu jarak. Terbukti dari pernyataan responden $\mathrm{p} 1, \mathrm{p} 7, \mathrm{p} 8, \mathrm{p} 9$ dengan rata-rata jawaban "kalau milih RS yah yang dekat dengan rumah dan pokok nya yang terdekat". Tema 2: Kelas BPJS

BPJS merupakan salah satu asuransi kesehatan yang meringankan beban masyrakat Indonesia dalam bidang kesehatan. Hal ini terbukti seusai dengan pernyataan responden $\mathrm{p} 1, \mathrm{p} 4, \mathrm{p} 9$ yaitu “ Bisa menggunakan BPJS dan rujukan karena BPJS".

Tema 3:Tarif

Tarif adalah salah satu faktor yang menjadikan salah satu alasan dalam pemilihan Rumah Sakit meskipun dalam penggunaan tarif telah disesuaikan dengan kebijakan yang ada. Hal ini terbukti dari pernyataan responden p4,p5,p11 yaitu "Gratis, biaya nya yang terjangkau dan tidak terlalu mahal".

Tema 4: Pelayanan

Pelayanan adalah setiap upaya yang diselenggarakan sendiri atau secara bersamasama dalam suatu organisasi untuk memelihara dan meningkatkan kesehatan, mencegah dan menyembuhkan penyakit serta memulihkan kesehatan perorangan, keluarga, 
kelompok dan atupun masyarakat. Pelayanan yang bagus menjadi salah satu faktor dalam pemilihan rumah sakit terbukti dari pernyataan responden p1,p2,p5,p11 yaitu "Pelayanan ramah, Penjelasan tidak berteletele dan perawatnya sopan, cepat dan bagus pelayanannya"

\section{Tema 5:Dokter}

Dokter merupakan komponen yang utama dalam layanan kesehatan di Rumah Sakit yang melayani individu dalam keadaan sakit dalam penentuan terapi serta penegakkan diagnose. Sesuai dengan pernyataan responden p2,p5,p6,p7,p11 yaitu’Dokternya yang lengkap, penegakkan diganosa yang tepat dan akurat pastinya”.

Tema 6 :Penyakit

Terdapat beberapa penyakit yang bisa ditangani dibeberapa rumah sakit terkait dengan adanya kertebatasan sarana dan prasarana dalam proses penyembuhan individu yang sakit. Sesuai dengan pernyataan responden p1,p11 yaitu: "tergantung sakitnya apa dan penyakitnya apa , ya dirawatnya dimana itu tergantung juga kan, gak semua RS bisa kan”.

Tema 7: Fasilitas

Fasilitas yang memadai akan menjadi pertimbangan dalam pemilihan Rumah Sakit sesuai dengan pernyataan responden p3,p4,p5,p7 yaitu: "Fasilitas yang lengkap dan yang bagus ya itu penting"

Hasil penelitian yang pertama dalam motivasi pemilihan rumah sakit oleh masyarakat dalam mendukung kesehatannya adalah yaitu Jarak. Menurut Kamus Besar Bahasa Indonesia (2008) jarak adalah ruang sela (panjang atau jauh) antara dua benda(Aditya, Solikhah and Kurniawan, 2019). Jarak adalah ukuran jauh dekatnya antara tempat yang satu dengan tempat yang lain dan diukur dengan satuan meter (Aditya, Qur'aniati and Krisnana, 2014). Jarak berkaitan dengan lokasi atau wilayah yang menjadi pusat pemenuhan kebutuhan manusia. Teori ini sejalan sesuai dengan penelitian ini, bahwa masyarakat memilih rumah sakit yang mempunyai jarak terdekat. Sesuai dengan teori Jannah, 2012 bahwa mempunyai keterkaitan dengan lokasi dalam pemenuhan kebutuhan (kesehatan)(Ika Widiastuti, 2017).

Jarak adalah faktor utama yang menjadi alasan dalam pemilihan Rumah Sakit selain jarak, faktor selanjutnya yaitu BPJS. BPJS merupakan program jaminan kesehatan yang diselenggarakan oleh pemerintah (Lusiana, Frinaldi and Putri, 2019). Program BPJS memiliki tujuan yaitu menjamin agar peserta memperoleh manfaat pemeliharaan 
kesehatan dan perlindungan dalam memenuhi kebutuhan dasar kesehatan. Hal ini sejalan sesuai dengan tujuan program tersebut bahwa masyarakat telah merasakan manfaat dari program tersebut yang membantu dalam permasalahan kesehatan di fasilitas umum Negara yaitu Rumah Sakit dan mesyarakat telah menggunakan program pemerintah tersebut.

BPJS lebih berfokus dalam penyelesaian masalah kesehatan terkait pemecahan masalah ekonomi salah satunya untuk meringankan biaya pengobatan. Biaya pengobatan sesuai dengan tarif rumah sakit tersebut(Kusumaningrum and Soewondo, 2018). Tarif rumah sakit diatur dalam Peraturan Menteri Kesehatan Republik Indonesia Nomor 85 Tahun 2015 tentang Pola Tarif Nasional Rumah Sakit. Masyarakat lebih memilih tarif rumah sakit yang biaya masih terjangkau, hal ini sejalan dengan peraturan menteri terkait dengan tarif bahwa terdapat kebijakan tertentu yang mengatur hal tersebut. Selain dalam peraturan tersebut, tarif suatu rumah sakit juga diatur dalam kebijakan rumah sakit tersebut, sehingga tarif setiap rumah sakit akan berbeda(Rokhaidah; Herlina, 2018).
Individu pengguna layanan umum seperti rumah sakit selain pada tarif, sesuai dengan data penelitian bahwa pertimbangan selanjutnya adalah pelayanan atau layanan yang diterima (Aditya et al., 2020). Menurut Keputusan Menteri Pendayagunaan Aparatur Negara Nomor 63 Tahun 2004, standar pelayanan sekurang-kurangnya meliputi : Prosedur Pelayanan, Waktu Penyelesaian, Biaya Pelayanan, Produk pelayanan, Sarana dan prasarana, Kompetisi petugas pemberi pelayanan. Standart pelayanan yang ada tersebut sejalan dengan penelitian yang telah dilakukan bahwa banyak masyarakat yang memilih rumah sakit sebagai tempat dalam menunjang kesehatannya lebih memilih rumah sakit yang memiliki standart pelayanan sesuai dengan aturan tersebut diatas(Intarti dkk, 2018).

Layanan didalam rumah sakit salah satu faktor penentu dalam pemilihan rumahs akit tersebut adalah dokter. Sesuai dengan UU Republik Indonesia Nomor 29 Tahun 2004 tentang Praktik Kedokteran. Setiap dokter harus memiliki kualifikasi Sertifikat kompetensi adalah surat tanda pengakuan terhadap kemampuan seorang dokter ataudokter gigi untuk menjalankan praktik kedokteran di seluruh Indonesia setelah lulus uji kompetensi, hal tersebut tercantum dalam 
UU Republik Indonesia Nomor 29 Tahun 2004 BAB 1 Pasal 1 Ayat 4. Hal ini sejalan dengan penelitian yang telah dilakukan bahwa setiap individu sakit dalam pemilihan rumah sakit terdapat pertimbangan terkait dengan kualitas dokter (Rodríguez-Huerta et al., 2019).

Setiap dokter yang melakukan pengobatan atau layanan kesehatan kepada individu sakit akan menegakkan diagnosa sehingga akan muncul penyakit yang telah dialami oleh individu sakit. Rumah sakit memiliki klasifikasi sesuai dengan Peraturan Menteri Republik Indonesia Nomor 56 Tahun 2004 tentang Klasifikasi dan Perizinan Rumah Sakit (Henriette et al., 2019). Hal ini sejalan dengan penelitian yang dilakukan oleh peneliti bahwa tidak semua rumah sakit menangani seluruh masalah/penyakit yang muncul pada individu sakit, terdapat klasifikasi yang telah tertuang dalam peraturan tersebut(Aditya, 2019a).

Klasfikasi rumah sakit yang ada, membuat fasilitas sarana dan pra sarana yang dimiliki setiap rumah sakit akan berbeda. Peraturan Menteri Republik Indonesia Nomor 4 tahun 2018 tentang Kewajiban Rumah sakit dan Kewajiban Pasien. Setiap rumah sakit harus memenuhi kriteria standart tersebut namun beberapa sarana prasarana lain penunjang tidak semua rumah sakit memilikinya. Hal tersebut sejalan dengan penelitian yang telah dilakukan oleh peneliti pertimbangan pemilihan rumah sakit juga terkait dengan kelengkapan fasilitas yang ada.

\section{KESIMPULAN}

Dalam Pemilihan Rumah Sakit jarak adalah faktor utama pertimbangan dalam pemilihan Rumah Sakit. Faktor selanjutnya adalah BPJS atau asuransi kesehatan yang dimiliki oleh setiap individu dalam pemilihan Rumah sakit karena hal tersebut akan berkaitan dengan tarif. rumah sakit yang mempengaruhi pengeluaran indvidu yang sakit. Asuransi tersebut adalah pemecahan masalah yang dapat diatasi oleh indivisu terkait dengan masalah ekonomi. Pertimbangan lain dalam pemilihan Rumah Sakit adalah layanan karena pelayanan yang didalamnya memiliki indikator penting seperti kualitas dokter, kelengkapan fasilitas, dan klasifikasi rumah sakit dalam proses perbaikan individu sakit sesuai dengan jenis penyakit, tidak semua rumah sakit memiliki fasilitas yang lengkap dalam menunjang proses kesembuhan individu sakit. Hal-hal tersebut adalah yang menjadi pertimangan individu dalam memilih Rumah Sakit. 


\section{DAFTAR RUJUKAN}

Aditya, R. S. et al. 2017. 'Experience of the Healthworkers in Conductin Methadone Rehabilitation Therapy at the Public Health Center', Dama International Journal Researchers (DIJR), 2(2), pp. 107-113.

Aditya, R. S. 2019a. 'Comparison Of List And Health Coaching Methods About Basic Life Support (Bls) For Teenagers', $J K E P, 4(1)$, pp. 5-10. Available at: http://ejurnal.poltekkesjakarta3.ac.id/ind ex.php/JKep/article/view/231/172.

Aditya, R. S. 2019b. Perbandingan Metode Health Coaching dan Ceramah Tentang Basic Life Support (BLS) Untuk Remaja Masjid, Jurnal Keperawatan BSI. Available at: http://ejurnal.univbsi.id/index.php/keper awatan/article/view/105 (Accessed: 1 November 2019).

Aditya, R. S. et al. 2020. Pengantar Antropologi Kesehatan. 1st edn. Edited by M. F. Arifin. Malang: Literasi Nusantara.

Aditya, R. S., Qur'aniati, N. and Krisnana, I. 2014. 'Influence of Health Education Short Film Media Lecture Methods on Knowledge, Attitudes, and Practices of Mother About Early Detection of Children Diphtheria Cases', Pediomaternal Nursing Journal.

Aditya, R. S., Solikhah, F. K. and Kurniawan, S. B. 2019. 'Teenager Response to the Conditions of Basic Level Emergency: A Phenomenology Study', Indian Journal of Public Health, 10(1), p. 170.

Henriette, I. et al. 2019. 'Intensive \& Critical Care Nursing Intensive care nurses ' experiences of withdrawal of lifesustaining treatments in intensive care patients: A qualitative study', Intensive \& Critical Care Nursing, (xxxx), p. 102768. doi: 10.1016/j.iccn.2019.102768.

Ika Widiastuti. 2017. 'SOCIAL SECURITY GUARANTEE (BPJS) SERVICES IN WEST JAVA', pp. 91-101. Available at: http://www.ghbook.ir/index.php?name=

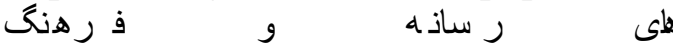
\& ذو وي ن ن \& ن nline \&book_id $=13650 \&$ page $=73 \&$ chkh ashk=ED9C9491B4\&Itemid=218\&lang $=$ fa\&tmpl=component.

Intarti dkk, W. D. 2018. 'Factors that Influence Utilization of Elderly Posyandu', Journal of Health Studies, 2(1), pp. 110-122. doi: 10.31101/jhes.439.

Kusumaningrum, F. and Soewondo, P. 2018. 'The Role of Health Insurance Against Utilization of Health Workers as Helpers in Childbirth in Indonesia', Jurnal Kesehatan Reproduksi, 9(2), pp. 109124. doi: 10.22435/kespro.v9i2.1092.109-124.

Lusiana, Y., Frinaldi, A. and Putri, N. E. 2019. 'THE EFFECT OF SERVICE QUALITY ON TRUST OF PBPU BPJS HEALTH CARE IN BPJS PADANG BRANCH HEALTH IN PADANG CITY', 2(1), pp. 86-96.

Rodríguez-Huerta, M. D. et al. 2019. 'An informative nursing intervention for families of patients admitted to the intensive care unit regarding the satisfaction of their needs: The INFOUCI study', Intensive and Critical Care Nursing, (xxxx). doi: 10.1016/j.iccn.2019.102755. 
Rokhaidah; Herlina .2018. 'Phenomenological Studies of Parents' Experiences in Caring for Children with a Cancer Diagnosis', Jurnal Kedokteran dan Kesehatan, pp. 31-38.

Yusuf, A. et al. 2017. Riset Kualitatif Dalam Keperawatan. 1st edn. Surabaya: Mitra Wacana Media. 